www.nature.com/cdd

\title{
The SR/ER-mitochondria calcium crosstalk is regulated by GSK3 $\beta$ during reperfusion injury
}

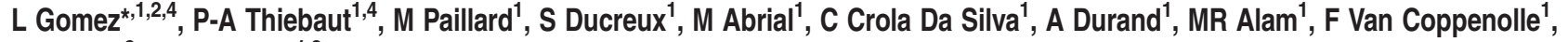 \\ S-S Sheu ${ }^{2}$ and M Ovize ${ }^{1,3}$
}

Glycogen synthase kinase-3 $\beta$ (GSK3 $\beta$ ) is a multifunctional kinase whose inhibition is known to limit myocardial ischemiareperfusion injury. However, the mechanism mediating this beneficial effect still remains unclear. Mitochondria and sarco/ endoplasmic reticulum (SR/ER) are key players in cell death signaling. Their involvement in myocardial ischemia-reperfusion injury has gained recognition recently, but the underlying mechanisms are not yet well understood. We questioned here whether GSK3 $\beta$ might have a role in the $\mathrm{Ca}^{2+}$ transfer from SR/ER to mitochondria at reperfusion. We showed that a fraction of GSK3 $\beta$ protein is localized to the SR/ER and mitochondria-associated ER membranes (MAMs) in the heart, and that GSK3 $\beta$ specifically interacted with the inositol 1,4,5-trisphosphate receptors $\left(\mathrm{IP}_{3} \mathrm{Rs}\right) \mathrm{Ca}^{2+}$ channeling complex in MAMs. We demonstrated that both pharmacological and genetic inhibition of GSK3 $\beta$ decreased protein interaction of $\mathrm{IP}_{3} \mathrm{R}$ with the $\mathrm{Ca}^{2+}$ channeling complex, impaired SR/ER $\mathrm{Ca}^{2+}$ release and reduced the histamine-stimulated $\mathrm{Ca}^{2+}$ exchange between SR/ER and mitochondria in cardiomyocytes. During hypoxia reoxygenation, cell death is associated with an increase of GSK3 $\beta$ activity and $\mathbb{P}_{3} R$ phosphorylation, which leads to enhanced transfer of $\mathrm{Ca}^{2+}$ from SR/ER to mitochondria. Inhibition of GSK3 $\beta$ at reperfusion reduced both $\mathrm{IP}_{3} \mathrm{R}$ phosphorylation and SR/ER $\mathrm{Ca}^{2+}$ release, which consequently diminished both cytosolic and mitochondrial $\mathrm{Ca}^{2+}$ concentrations, as well as sensitivity to apoptosis. We conclude that inhibition of GSK3 $\beta$ at reperfusion diminishes $\mathrm{Ca}^{2+}$ leak from $\mathbb{I P}_{3} \mathrm{R}$ at MAMs in the heart, which limits both cytosolic and mitochondrial $\mathrm{Ca}^{2+}$ overload and subsequent cell death.

Cell Death and Differentiation (2016) 23, 313-322; doi:10.1038/cdd.2015.101; published online 24 July 2015

Glycogen synthase kinase-3 (GSK3) was originally identified as a phosphorylating kinase for glycogen synthase. ${ }^{1,2}$ It has two isoforms, $a$ and $\beta$, that possess strong homology in their kinase domains with, however, distinct functions. ${ }^{3}$ GSK3 is constitutively active but it can be inhibited by phosphorylation on serine 21 (Ser21) for GSK3a and Ser9 for GSK3 $\beta .{ }^{4}$ In the heart, GSK3 $\beta$ has several important roles in cardiac hypertrophy ${ }^{5}$ and ischemia-reperfusion (IR) injury. ${ }^{6}$ Accumulating evidence indicates that phospho-Ser9GSK3 $\beta$-mediated cytoprotection is achieved by an increased threshold for permeability transition pore (PTP) opening. ${ }^{6-9}$ The mechanism by which GSK3 $\beta$ delays PTP opening still remains unclear. It has been reported that GSK3 $\beta$ could interact with ANT at the inner mitochondrial membrane in the heart $^{9}$ and/or to phosphorylate voltage-dependent anion channel (VDAC) and cyclophilin D (CypD) in cancer cells. ${ }^{10,11}$ GSK3 $\beta$ also has other proposed mechanisms of action, including a poorly characterized role in calcium $\left(\mathrm{Ca}^{2+}\right)$ homeostasis regulation ${ }^{12}$ and protein-protein interactions, ${ }^{9}$ as well as functions in different subcellular fractions such as the nucleus, cytosol and mitochondria. ${ }^{13}$
Reperfusion is the most powerful intervention to salvage ischemic myocardium. However, it can also paradoxically lead to cardiomyocyte injury and death. ${ }^{14}$ One of the main actors of this lethal reperfusion injury is cellular $\mathrm{Ca}^{2+}$ overload, ${ }^{15}$ which results in part from excessive sarco/endoplasmic reticulum (SR/ER) $\mathrm{Ca}^{2+}$ release and $\mathrm{Ca}^{2+}$ influx through the plasma membrane (e.g. through L-type $\mathrm{Ca}^{2+}$ channel and $\mathrm{NCX}$ (sodium-calcium exchanger)). ${ }^{16}$ Although ryanodine receptors (RyRs) are the major cardiac SR/ER $\mathrm{Ca}^{2+}$-release channels involved in excitation-contraction coupling $(E C C)^{17}$ and ischemia-reperfusion (IR) injury, ${ }^{18}$ recent studies reported an increasing role for inositol 1,4,5-trisphosphate receptors $\left(\mathrm{IP}_{3} \mathrm{Rs}\right) \mathrm{Ca}^{2+}$-release channels in the modulation of ECC and cell death. ${ }^{19,20} \mathrm{Ca}^{2+}$-handling proteins of ER and mitochondria are highly concentrated at mitochondria-associated ER membranes (MAMs), providing a direct and proper mitochondrial $\mathrm{Ca}^{2+}$ signaling, including VDAC, Grp75 and $\mathrm{IP}_{3} \mathrm{R} 1 .^{20-22}$

Here, we provide evidence that, following IR, a fraction of cellular GSK3 $\beta$ is localized at the SR/ER and MAMs. At the MAMs interface, GSK3 $\beta$ can specifically interact and regulate the protein composition of the $\mathrm{IP}_{3} \mathrm{R} \mathrm{Ca}^{2+}$ channeling complex

\footnotetext{
${ }^{1}$ INSERM UMR-1060, Laboratoire CarMeN, Université Lyon 1, Faculté de medicine, Rockefeller et Charles Merieux Lyon-Sud, Lyon 69003, France; ${ }^{2}$ Department of Medicine, Center for Translational Medicine, Sidney Kimmel College, Thomas Jefferson University, Philadelphia, PA 19107, USA and ${ }^{3}$ Hospices Civils de Lyon, Hôpital Louis Pradel, Service d'Explorations Fonctionnelles, Cardiovasculaires and CIC de Lyon, Lyon 69394, France

${ }^{*}$ Corresponding author: L Gomez, INSERM UMR-1060, Laboratoire CarMeN, Université Lyon 1, Faculté de Medicine, Rockefeller et Charles Merieux Lyon-Sud, Lyon 69003, France. Tel: +33 4787770 47; Fax: +33 47877 71 75; E-mail: ludovic.gomez@inserm.fr

${ }^{4}$ These authors contributed equally to this work.

Abbreviations: ANT, adenine nucleotide translocator; $\mathrm{Ca}^{2+}$, calcium; CTRL, control; CypD, cyclophilin D; ER, endoplasmic reticulum; GSK3 $\beta$, glycogen synthase kinase$3 \beta$; HR, hypoxia reoxygenation; MAM, mitochondria-associated ER membranes; MTS, mitochondrial targeting sequence; PTP, permeability transition pore; IP ${ }_{3} R$, inositol 1,4,5-trisphosphate receptor; IR, ischemia-reperfusion; RyR, ryanodine receptor; SB21, SB216763; Ser, serine; SR/ER, sarco/endoplasmic reticulum; Tyr, tyrosine; VDAC, voltage-dependent anion channel; WT, wild type

Received 09.6.15; accepted 22.6.15; Edited by L Scorrano; published online 24.7.15
} 
and modulate $\mathrm{Ca}^{2+}$ transfer between SR/ER and mitochondria. These findings support a novel mechanism of action of GSK3 $\beta$ in cell death process during reperfusion injury.

\section{Results}

GSK3 $\beta$ interacts with the $\mathrm{IP}_{3} \mathrm{R} \mathrm{Ca}^{2+}$ channeling complex at the SR/ER-mitochondria interface in the heart. To characterize the role of GSK3 $\beta$ in the heart, we first determined its subcellular localization. The purity of SR/ER, mitochondrial and MAM fractions from mouse hearts were visualized by both electron microscopy (Supplementary Figure S1) and validated by western blot (WB) (Figure 1a). GSK3 $\beta$ was detected in both SR/ER and mitochondria and more particularly in the MAMs fraction together with $I P_{3} R$, Grp75, VDAC and CypD. To characterize the implication of GSK3 $\beta$ in MAM fraction, we performed two-dimensional blue native page separation on heart homogenates. Our results showed that although GSK3 $\beta$ was present in varying amounts in complexes, a pool of GSK3 $\beta$ was also present in a higher molecular weight complex encompassing $I P_{3} R$, Grp75, VDAC and CypD (Figure 1b, arrow), suggesting that GSK3 $\beta$ interacts with MAM-resident proteins to form a macrocomplex in native state in the heart.

To confirm the involvement of GSK3 $\beta$ in MAM protein complex, we next investigated its relationship with CypD, VDAC, Grp75 and IP ${ }_{3} \mathrm{R}$ at the MAM interface. ${ }^{21}$ Using in situ proximity ligation assay (PLA), we first validated that GSK3 $\beta$ interacted with $I P_{3} R$, Grp75, VDAC or CypD but not RyR2 and ANT in both adult cardiomyocytes and H9c2 cells (Supplementary Figure S2A). GSK3 $\beta$ inhibitors were used to determine if it might change these protein interactions. As shown in Supplementary Figures S2A and B, both pharmacological and genetic inhibition of GSK3 $\beta$ decreased the interaction of GSK3 $\beta$ with $\mathrm{IP}_{3} \mathrm{R}$, Grp75, VDAC or CypD. Interestingly, the inhibition of GSK3 $\beta$ also modified the interaction between the other partner proteins of the complex; indeed, SB216763 (SB21) significantly reduced the co-immunoprecipitation (IP) of $\mathrm{IP}_{3} \mathrm{R}$ with $\mathrm{GSK} 3 \beta$, as well as Grp75, VDAC and CypD in heart homogenates (Figure 1c). In line with this, using PLA approach, adult cardiomyocytes treated with SB21 displayed significantly decreased interaction of GSK3 $\beta$, Grp75, VDAC and CypD with $I_{3} R$ (Figure 1d). Altogether, these results suggest that GSK3 $\beta$ modulates the $\mathrm{IP}_{3} \mathrm{R}-\mathrm{Ca}^{2+}$ channeling complex at the MAM interface in the heart.

Inhibition of GSK3 $\beta$ alters $\mathrm{Ca}^{2+}$ transfer from SR/ER to mitochondria in cardiomyocytes. We next examined the role of GSK3 $\beta$ on the transfer of $\mathrm{Ca}^{2+}$ between SR/ER and mitochondria. Calcium fluxes were monitored in isolated adult mouse cardiomyocytes stained with rhod-2 fluorescent dye. In our model, fluorescent dye showed a specific mitochondrial staining, overlapping with the mitochondrial marker Mitotracker Green (Figure 2a). The quantitative pixel-by-pixel analysis measured with Zen software (Zeiss, Germany) showed strong correlation between rhod-2 and Mitotracker Green with an overlap coefficient averaging $0.89 \pm 0.01$ (0 corresponds to no overlap and 1 corresponds to a perfect overlap) (Figure 2a). Under basal conditions, $100 \mu \mathrm{M}$ histamine induced a transient $\mathrm{Ca}^{2+}$ release from SR/ER, which consequently induced mitochondrial $\mathrm{Ca}^{2+}$ uptake in adult cardiomyocytes (Figure $2 b$ ), reflecting the $I P_{3} R$ mediated $\mathrm{Ca}^{2+}$ transfer from SR/ER to mitochondria. This $\mathrm{Ca}^{2+}$ transfer was significantly reduced when GSK3 $\beta$ was inhibited by SB21 averaging $0.60 \pm 0.06$ - versus $1.00 \pm 0.07$ fold versus control (CTRL); $P<0.05$ (Figure $2 b$ ). Interestingly, the inhibition of GSK3 $\beta$ by SB21 did not modify the caffeineinduced $\mathrm{Ca}^{2+}$ transfer from $\mathrm{SR} / \mathrm{ER}$ to mitochondria $(P=\mathrm{NS}$, Figure 2c), suggesting that GSK3 $\beta$ has a specific action on $\mathrm{IP}_{3} \mathrm{R}$ channels with no effect on RyRs in adult cardiomyocytes. As adult mice cardiomyocytes are refractory to transfection using conventional methods and that they can only be maintained in culture for short periods before they dedifferentiate, ${ }^{23}$ the analysis on adult cardiomyocytes was complemented by a number of assays on $\mathrm{H} 9 \mathrm{c} 2$ cells to define the role of GSK3 $\beta$ in the regulation of $\mathrm{Ca}^{2+}$ transfer between SR/ER and mitochondria. Similar to adult cardiomyocytes, rhod-2 showed a specific mitochondrial staining in $\mathrm{H} 9 \mathrm{c} 2$ cells with an overlap coefficient averaging $0.87 \pm 0.02$ when compared with Mitotracker Green (Supplementary Figure S3A). As shown previously, SB21 did not modulate the mitochondrial $\mathrm{Ca}^{2+}$ amplitude induced by caffeine $(P=\mathrm{NS}$, Supplementary Figure S3B), but significantly reduced the $\mathrm{Ca}^{2+}$ transfer under histamine stimulation in $\mathrm{H} 9 \mathrm{c} 2$ cells (Supplementary Figures S3C and S5). Although the knockdown of GSK3 $\beta$ significantly reduced the amplitude of $\mathrm{Ca}^{2+}$ into mitochondria averaging $0.36 \pm 0.01$ - versus $1.00 \pm 0.10$-fold with SiC; $P<0.05 \quad$ (Supplementary Figure S3D), the overexpression of $\mathrm{GSK} 3 \beta$ in $\mathrm{H} 9 \mathrm{c} 2$ cells significantly enhanced the $\mathrm{Ca}^{2+}$ transfer into mitochondria when compared with its respective control averaging $1.52 \pm 0.07$ versus $1.00 \pm 0.04$ in the pcDNA group; $P<0.05$ (Supplementary Figure S3E). These results were further confirmed using a mitochondrially targeted $\mathrm{Ca}^{2+}$ probe (Mitycam, Glasgow, Scotland, UK), suggesting that GSK3 $\beta$ specifically controls and regulates the $I_{3} R$-mediated SR/ER $\mathrm{Ca}^{2+}$ transfer to mitochondria in cardiac cells.

To rule out a potential depolarization of mitochondria under GSK3 $\beta$ inhibition, we stained cardiac cells with TMRM to analyze mitochondrial membrane potential. Neither the pharmacological nor the genetic inhibition of GSK3 $\beta$ modified the mitochondrial membrane potential of cells (Supplementary Figures S4A and B), indicating that the observed reduction of $\mathrm{Ca}^{2+}$ transfer from SR/ER to mitochondria was not the consequence of a diminution of the driving force between the two organelles.

Inhibition of GSK3 $\beta$ at reoxygenation limits both cytosolic and mitochondrial $\mathrm{Ca}^{2+}$ overload by reducing $\mathrm{Ca}^{2+}$ release from SR/ER. It has been previously demonstrated that inhibition of GSK3 $\beta$ at reperfusion is cardioprotective by preventing PTP opening. ${ }^{6,7}$ However, the relative cardioprotective mechanism still remains unknown. We here hypothesized that this beneficial effect might be linked to the limitation of both cytosolic and mitochondrial $\mathrm{Ca}^{2+}$ overload (and subsequent $\mathrm{Ca}^{2+}$-dependent PTP opening) by reducing $\mathrm{Ca}^{2+}$ release from $\mathrm{IP}_{3} \mathrm{R}$ at reperfusion. 


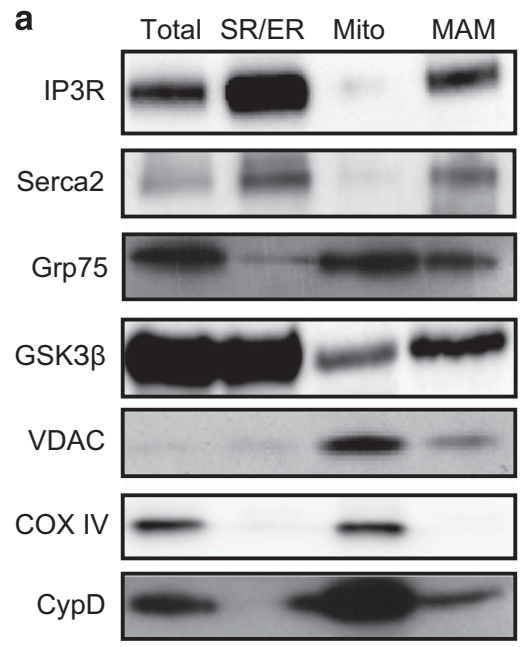

b
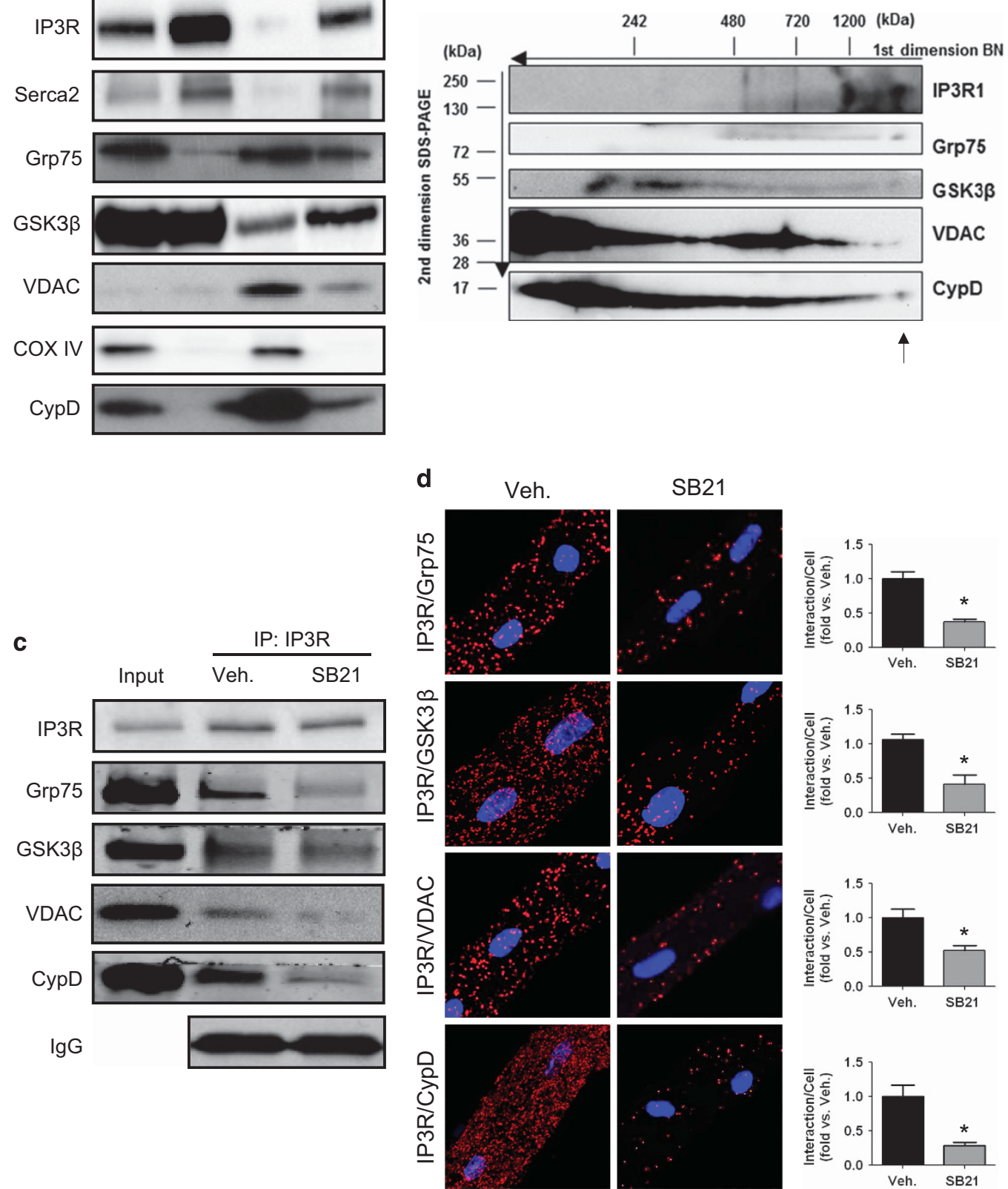

Figure 1 GSK3 $\beta$ modulates the $\mathrm{IP}_{3} \mathrm{R}-\mathrm{Ca}^{2+}$ channeling complex at MAMs in the heart. (a) Protein components of subcellular fractions prepared from WT mouse hearts revealed the presence of GSK3 $\beta$ in MAMs. Total, total heart homogenate; Mito, pure mitochondria; MAM, mitochondria-associated ER membranes. IP ${ }_{3} R$ and SERCA2 were used as cardiac SR/ER biomarkers. VDAC, Grp75, COXIV and CypD were used as mitochondrial biomarkers. (b) Two-dimensional blue native protein separation of WT heart homogenates. GSK3 $\beta$ was clearly detected in a high molecular weight complex encompassing IP ${ }_{3} R$, Grp75, VDAC and CypD (arrow). (c) IP revealed that SB21 (a potent GSK3 $\beta$ inhibitor, $70 \mu \mathrm{g} / \mathrm{kg}$ ) reduced the interaction of $\mathrm{IP}_{3} \mathrm{R}$ with Grp75, GSK3 $\beta$, VDAC and CypD in mice hearts (one representative out of $n=3$ is shown). (d) Typical images of in situ interactions between $\mathrm{P}_{3} \mathrm{R}$ with Grp75, GSK3 $\beta$, VDAC and CypD using PLA in adult cardiomyocytes with or without SB21 treatment $(6 \mu \mathrm{M})$. Quantification of the PLA red fluorescent dots was performed using BlobFinder V.3.2 and nuclei were stained in blue with 4',6-diamidino-2-phenylindole (DAPI). Indicated results are means \pm S.E.M. of three distinct experiments (each experiment represents the average of $8-10$ adult cardiomyocytes). ${ }^{*} P<0.05$ versus vehicle (Veh)

To test our hypothesis, we started by investigating reticular (ER), cytosolic and mitochondrial $\mathrm{Ca}^{2+}$ homeostasis after hypoxia reoxygenation (HR) in $\mathrm{H} 9 \mathrm{c} 2$ cells. In the control group $(\mathrm{HR}), 4 \mathrm{~h}$ hypoxia followed by $2 \mathrm{~h}$ reoxygenation induced a significant cell death averaging $50.4 \pm 2.9 \%$ versus $7.4 \pm 0.5 \%$ in basal group; $P<0.05$ (Figure 3a). As expected, SB21 (6 $\mu \mathrm{M}$ ) at reoxygenation significantly reduced the cell death by half-averaging $25.9 \pm 1.8 \%$ versus $50.4 \pm 2.9 \%$ in the $\mathrm{HR}$ group (Figure 3a).

The ER $\mathrm{Ca}^{2+}$ level (measured with D1ER sensor ${ }^{24}$ ) was significantly higher in cells treated with SB21 at reoxygenation averaging $2.19 \pm 0.10$ versus $1.44 \pm 0.11$ in the HR group (Figure $3 b$ ). After addition of thapsigargin, the efflux of ER $\mathrm{Ca}^{2+}$ was 2.5-fold higher in the HR+SB21 group compared 
a

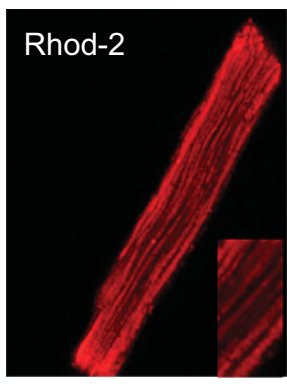

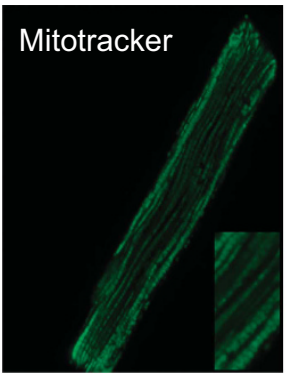

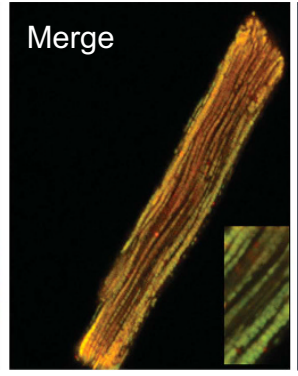

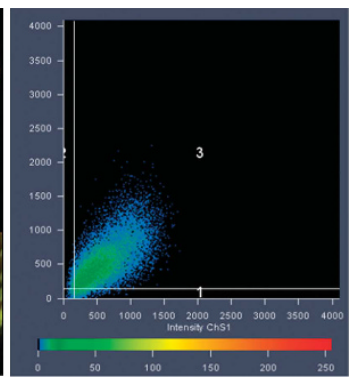

b
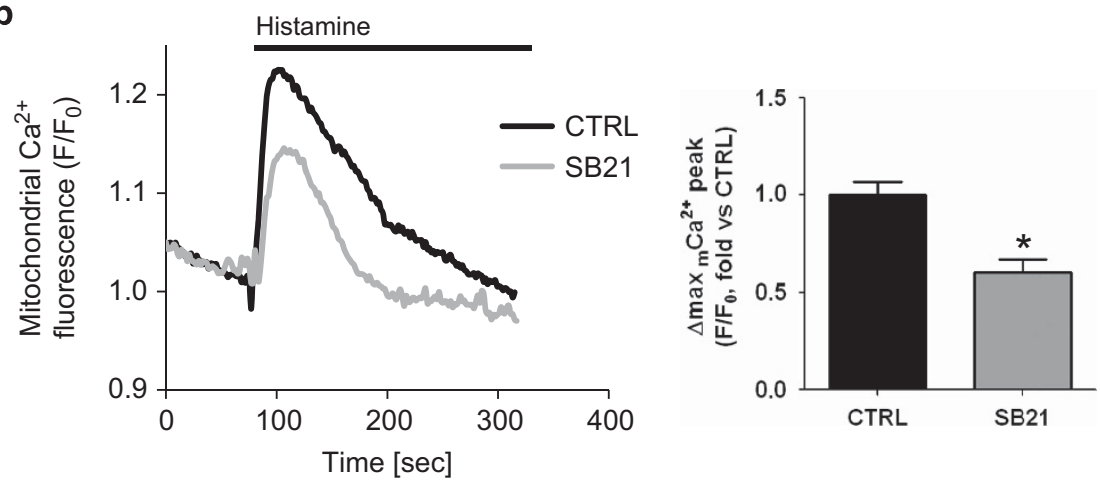

C
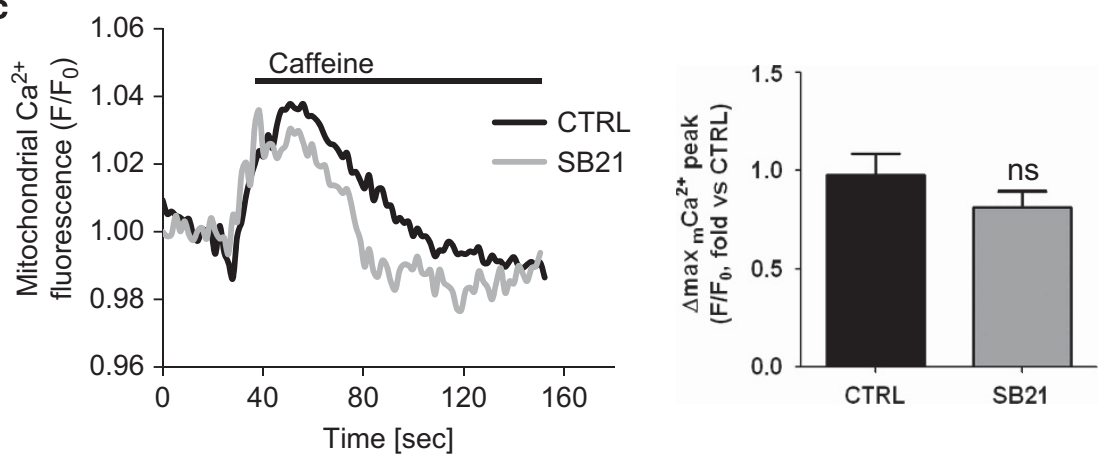

Figure 2 GSK3 $\beta$ regulates the SR/ER-mitochondria $\mathrm{Ca}^{2+}$ transfer through $\mathrm{IP}_{3} \mathrm{R}$ in adult cardiomyocytes. (a) Adult cardiomyocytes were loaded with the $\mathrm{Ca}^{2+}$ indicator rhod-2 and MitoTracker Green. Merge signal revealed a mitochondrial pattern, especially apparent in enlarged insets. (Right) The quantitative pixel-by-pixel analysis measured with Zen software showed strong correlation between rhod-2 and Mitotracker Green with an overlap coefficient averaging $0.89 \pm 0.01$. (b) Representative traces of mitochondrial $\mathrm{Ca}^{2+}$ transients. Adult cardiomyocytes were challenged with $100 \mu \mathrm{M}$ histamine to induce $\mathrm{Ca}^{2+}$ release from the ER. Mitochondrial $\mathrm{Ca}^{2+}$ transfer was significantly reduced under GSK3 $\beta$ inhibition (SB21). (c) Time scan of mitochondrial $\mathrm{Ca}^{2+}$ challenged with caffeine stimulation (5 mM) showed that inhibition of GSK3 $\beta$ did not modify the caffeine-induced Ca ${ }^{2+}$ transfer from SR/ER to mitochondria. Maximal mitochondrial $\mathrm{Ca}^{2+}$ peak fluorescence are expressed as means \pm S.E.M. ${ }^{*} P<0.05$ versus respective control $(n=5-6$ distinct experiments; each experiment represents the average of 8-12 adult cardiomyocytes)

with the HR group (Figure $3 b$ ), reinforcing the notion that inhibition of GSK3 $\beta$ at reoxygenation increases the steadystate $\left[\mathrm{Ca}^{2+}\right]$ in ER lumen during $\mathrm{HR}$.

As a consequence, the basal cytosolic $\mathrm{Ca}^{2+}$ measured with the ratiometric dye fura-2 was significantly reduced in the $\mathrm{HR}+\mathrm{SB} 21$ group averaging $0.30 \pm 0.02$ versus $0.38 \pm 0.01$ in the HR group; $P<0.05$ (Figure 3c), and the $I P_{3} R$-mediated $\mathrm{Ca}^{2+}$ transfer from SR/ER to mitochondria was significantly abolished when GSK3 $\beta$ was inhibited at reoxygenation averaging $1.05 \pm 0.02$ versus $1.10 \pm 0.03$ in the HR group; $P<0.05$ (Figure 3d). Altogether, these results indicate that SB21dependent cell protection is associated with a limitation of both cytosolic and mitochondrial $\mathrm{Ca}^{2+}$ overload likely through a reduction of $\mathrm{Ca}^{2+}$ release from $\mathrm{SR} / \mathrm{ER}$ at reoxygenation.
IP $P_{3} R$ is a downstream substrate of GSK3 $\beta$ during IR injury. We then sought to determine the mechanism by which GSK3 $\beta$ regulates $I P_{3} R$ in the heart. $A s I P_{3} R$ s are known to contain the GSK3 $\beta$ consensus sequence (Ser/Thr-XXXpSer/Thr) for phosphorylation (at Ser ${ }_{1756}$ ) that activates $I_{3} R$, we next questioned whether $\mathrm{IP}_{3} \mathrm{R}$ might be phosphorylated by GSK3 $\beta$ at the SR/ER-mitochondria interface in the heart. To test this hypothesis, we investigated the posttranslational modification of $\mathrm{IP}_{3} \mathrm{R}$ in adult cardiomyocytes during $\mathrm{HR}$.

As expected, HR induced a significant cell death averaging $65.3 \pm 3.2 \%$ versus $13.6 \pm 0.7 \%$ in the basal group (Figure 4a). Concomitantly, we observed a significant increase in phosphorylation of GSK3 $\beta$ at tyrosine $216\left(\mathrm{Tyr}_{216}\right)$ residue (known to facilitate GSK3 $\beta$ activity) averaging $1.82 \pm 0.08$ - 

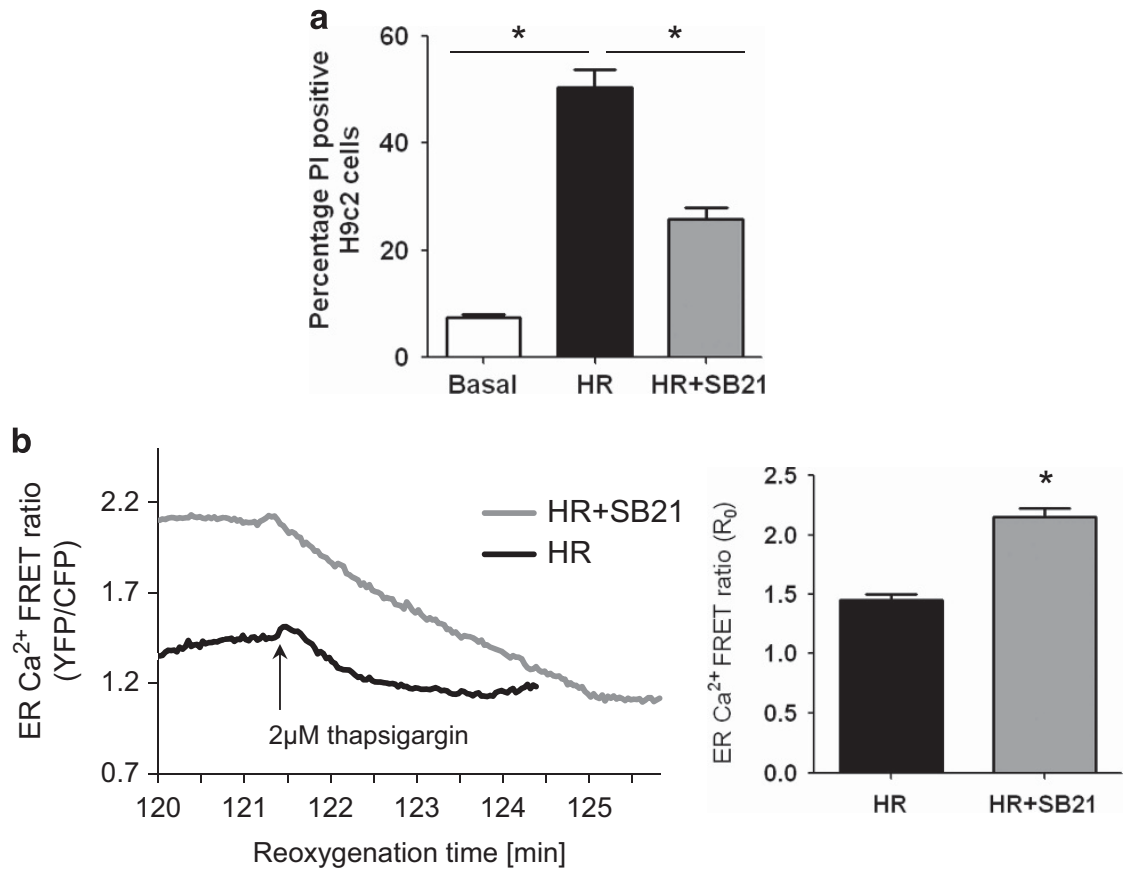

C

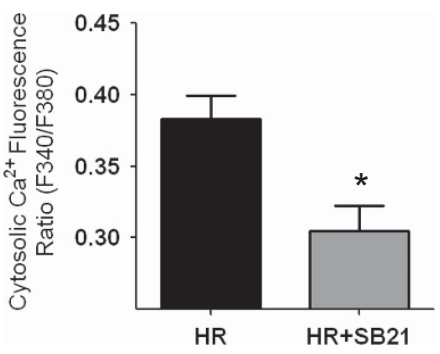

d

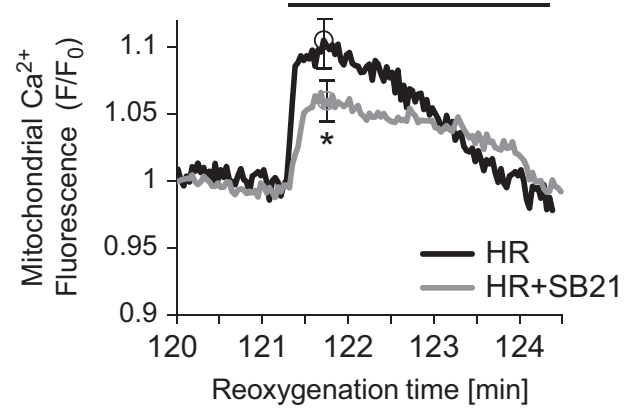

Figure 3 GSK3 $\beta$ regulates the SR/ER Ca ${ }^{2+}$ homeostasis at reoxygenation in H9c2 cells. (a) Cell viability measured with propidium iodide revealed that SB21 clearly protected $\mathrm{H} 9 \mathrm{c} 2$ cells against reoxygenation injury. Bar graphs were presented as the mean \pm S.E.M. ( $n=4$ distinct experiments per group). ${ }^{*} P<0.05$. (b) Representative curves of SR/ER Ca ${ }^{2+}$ FRET ratio in hypoxic H9c2 cells. After $2 \mathrm{~h}$ reoxygenation, $\mathrm{ER} \mathrm{Ca}{ }^{2+}$ level was significantly higher in cells treated with SB21 $(6 \mu \mathrm{M})$ at reoxygenation. Indicated results are means \pm S.E.M. of 4-6 distinct experiments (each experiment represents the average of 6-8 H9c2 cells). The addition of thapsigargin $(2 \mu \mathrm{M})$ induced an $\mathrm{ER} \mathrm{Ca}{ }^{2+}$ efflux, which was 2.5 -fold higher in the HR+SB21 group compared with the HR group (arrow). (c) Measurement of cytosolic $\mathrm{Ca}^{2+}$ at the end of reoxygenation with fura-2 (5 $\left.\mu \mathrm{M}\right)$ with or without SB21 $(6 \mu \mathrm{M})$. Results are means \pm S.E.M. of 4-5 distinct experiments. (Each experiment represents the average of $20-30 \mathrm{H} 9 \mathrm{c} 2$ cells.) ${ }^{*} P<0.05$ versus HR. (d) Representative curves of the time scan of mitochondrial $\mathrm{Ca}^{2+}($ rhod-2, $2.5 \mu \mathrm{M})$ upon histamine stimulation $(100 \mu \mathrm{M})$ after HR with or without SB21 at reoxygenation. Peak mitochondrial $\mathrm{Ca}^{2+}$ amplitude is expressed as means \pm S.E.M. ${ }^{*} P<0.05$ versus $\mathrm{HR}$ ( $n=5-6$ distinct experiments; each experiment represents the average of $8-12 \mathrm{H} 9 \mathrm{c} 2$ cells)

versus $1.00 \pm 0.05$-fold in the basal group; $P<0.05$ (Figure $4 \mathrm{~b}$ ). At reoxygenation, SB21 significantly reduced both cell death (around 50\%; Figure 4a) and phosphorylation at $\mathrm{Tyr}_{216}$ of GSK3 $\beta$ averaging $1.18 \pm 0.10$ versus $1.82 \pm 0.08$ in the HR group (Figure $4 \mathrm{~b}$ ). These results suggest that GSK3 $\beta$ activity is linked with cell death of adult cardiomyocytes during $H R$.

$\mathrm{HR}$ induced a significant increase of $\mathrm{IP}_{3} \mathrm{R}$ phosphorylation of Ser $_{1756}$, which was markedly reduced by SB21 at reoxygenation averaging $6.24 \pm 0.42$ - and $1.32 \pm 0.12$-fold versus basal, respectively (Figure $4 c$ ). The decreased $I P_{3} R$ phosphorylation and the consecutive limitation of its activity seem to be an important mechanism in the protection of cardiomyocytes elicited by GSK3 $\beta$ inhibition at reoxygenation. This idea was supported by the protein-protein interaction of GSK $3 \beta$ with $\mathrm{IP}_{3} \mathrm{R}$ in cardiomyocytes during $\mathrm{HR}$. Indeed, using the PLA approach, our data showed that HR doubled the interaction of GSK3 $\beta$ with $\mathrm{IP}_{3} \mathrm{R}$ averaging $2.23 \pm 0.23$ - versus $1.0 \pm 0.19$-fold in basal (Figure $4 d$ ). SB21 reduced this interaction at reoxygenation averaging $0.74 \pm 0.10$ versus $2.23 \pm 0.23$ in the HR group $(P<0.05$, Figure $4 d)$, suggesting that $I P_{3} R$ might be a downstream substrate of GSK3 $\beta$ during HR injury.

Eventually, we tested whether GSK3 $\beta$ regulates the posttranslational modification of $\mathrm{IP}_{3} \mathrm{R}$ during in vivo $\mathrm{IR}$ injury in a mouse model. As previously demonstrated by our group, ${ }^{6,7}$ mice treated with SB21 at reperfusion (IR+SB21, $70 \mu \mathrm{g} / \mathrm{kg}$ ) exhibit a significant reduction of infarct size after prolonged IR injury when compared with control (IR), averaging $31.0 \pm 0.6 \%$ versus $44.6 \pm 1.7 \%$, respectively (Figure $5 \mathrm{a}$ ). SB21 administered at reperfusion significantly decreased the phosphorylation of both GSK3 $\beta\left(\operatorname{Tyr}_{216}\right)$ and $\mathrm{IP}_{3} \mathrm{R}\left(\mathrm{Ser}_{1756}\right)$ induced by reperfusion injury (Figures $5 b$ and $c$ ), suggesting that GSK3 $\beta$ controls the extent of infarct size through the regulation of the 

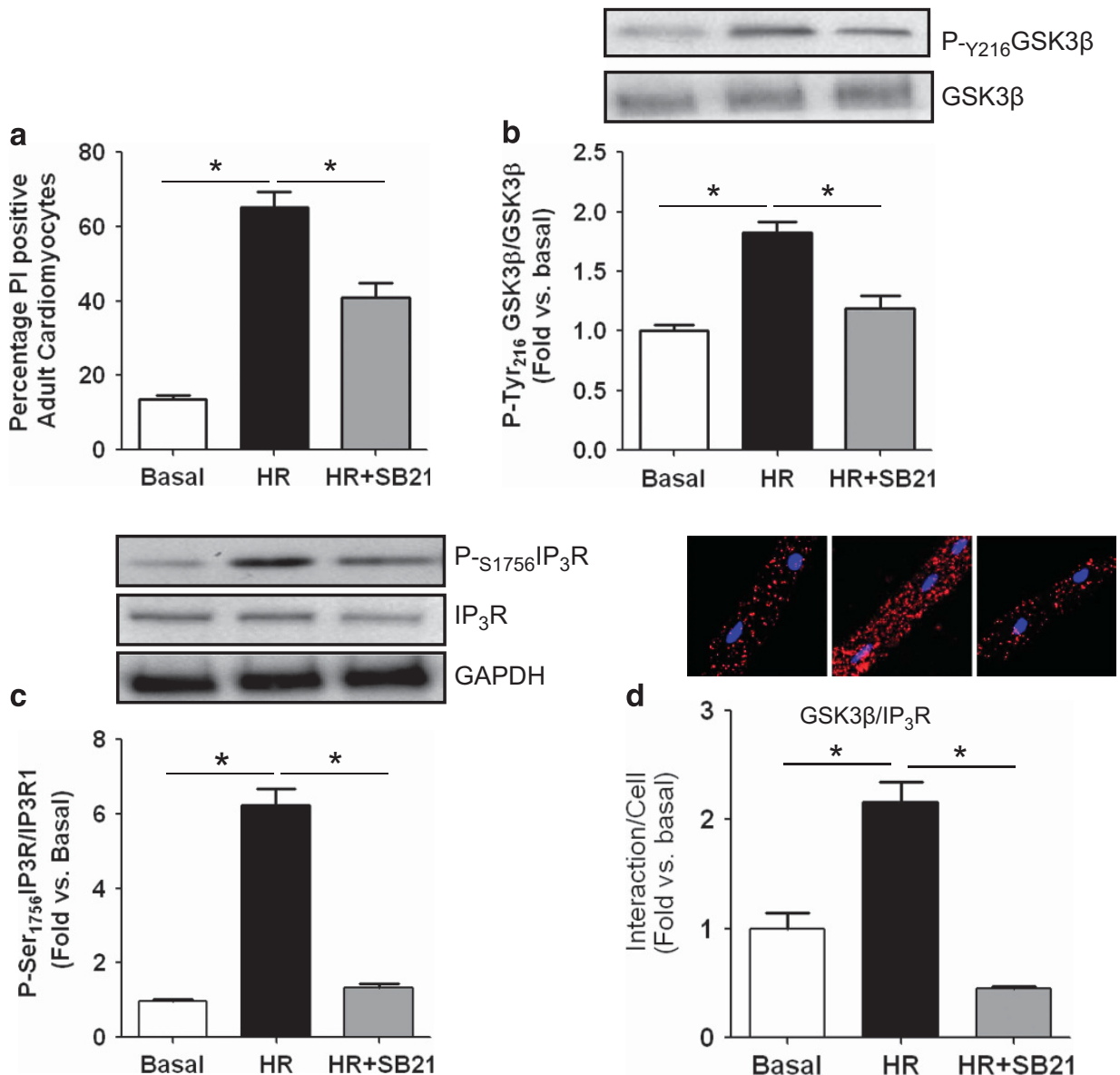

Figure 4 GSK3 $\beta$ inhibition at reoxygenation reverses the activation of $I P_{3} R$ induced by $H R$ in adult cardiomyocytes. (a) Cell viability measured with propidium iodide revealed that SB21 clearly protected adult cardiomyocytes against reoxygenation injury $(n=4$ distinct experiments per group); mean \pm S.E.M. of cell death is shown as percentage. ${ }^{*} P<0.05$. (b) GSK3 $\beta$ activity quantified by western immunoblotting of phospho-GSK3 $\beta$ ( $\operatorname{Tyr}_{216}$, active form) under hypoxic conditions. Results were normalized with total GSK3 $\beta$ ( $n=4-5$ distinct experiments per group). ${ }^{*} P<0.05$. (c) Immunoblotting of relative expression of phosphor-Ser ${ }_{1756} I_{3} R$ normalized with total $I P_{3} R$ during $H R$ injury. Results expressed as fold versus basal are means \pm S.E.M. ${ }^{*} P<0.05$ ( $n=4$ distinct experiments). (d) In situ protein interactions using PLA in adult cardiomyocytes revealed that SB21 $(6 \mu \mathrm{M})$ significantly reduced the interaction of $G S K 3 \beta$ with $\mathrm{IP}_{3} \mathrm{R}$ induced by HR. Results are expressed as means \pm S.E.M. of 8-10 distinct experiments (each experiments represent the average of $4-8$ adult cardiomyocytes). ${ }^{*} P<0.05$

phosphorylation state of $\mathrm{IP}_{3} \mathrm{R}$ at reperfusion. The in vivo link between $G S K 3 \beta$ and $I_{3} R$ was further reinforced by the reduction of $\mathrm{IP}_{3} \mathrm{R}$ co-IP with the partner of the $\mathrm{Ca}^{2+}$ channeling complex at MAMs including GSK3 $\beta$, as well as Grp75, VDAC and CypD in the area at risk of ischemic hearts treated with SB21 at reperfusion (Figure 5d).

\section{Discussion}

The present results suggest that (1) a fraction of GSK3 $\beta$ is localized at the SR/ER-mitochondria interface in the heart; (2) GSK $3 \beta$ regulates the $\mathrm{IP}_{3} \mathrm{R}$-dependent $\mathrm{Ca}^{2+}$ transfer from SR/ ER to mitochondria in cardiac cells and (3) cardioprotection mediated by GSK3 $\beta$ inhibition limits both cytosolic and mitochondrial $\mathrm{Ca}^{2+}$ overload by limiting $\mathrm{IP}_{3} \mathrm{R}$ channel opening at reperfusion.

We examined whether inhibition of GSK3 $\beta$ might protect the heart from reperfusion injury. ${ }^{7}$ Our results point to a regulatory effect of GSK3 $\beta$ on the $\mathrm{Ca}^{2+}$ transfer between SR/ER and mitochondria at the MAMs interface during IR injury.
In the heart, although a mitochondrial targeting sequence (MTS) has not been identified in GSK3 $\beta$, it has been recently demonstrated that an N-terminal domain of GSK3 $\beta$ could function as an MTS, permitting the translocation of GSK3 $\beta$ to mitochondria in a kinase-activity-dependent manner to regulate mitochondrial functions. ${ }^{13}$ Here, we show that a fraction of GSK3 $\beta$ is located in SR/ER and MAMs. We demonstrated that GSK $3 \beta$ physically interacts with the $\mathrm{IP}_{3} \mathrm{R}-\mathrm{Ca}^{2+}$ channeling complex including VDAC, Grp75, CypD and $\mathrm{IP}_{3} \mathrm{R}$ at MAMs. Moreover, we found that pharmacological and siRNAmediated inhibition of GSK3 $\beta$ altered the interaction among proteins of the $\mathrm{IP}_{3} \mathrm{R}-\mathrm{Ca}^{2+}$ channeling complex, suggesting a role for GSK3 $\beta$ in the structure of this complex.

We observed that GSK3 $\beta$ does not interact with RyRs, and the RyR-dependent $\mathrm{Ca}^{2+}$ release does not seem to be affected by GSK3 $\beta$ inhibition in cardiac cells. The inhibition of GSK3 $\beta$ was sufficient to reduce the $\mathrm{Ca}^{2+}$ transfer from $\mathrm{SR} / \mathrm{ER}$ to mitochondria via a specific action on $\mathrm{IP}_{3} \mathrm{R} \mathrm{Ca}^{2+}$ leak channels at MAMs. One can therefore question the respective importance of $\mathrm{IP}_{3} \mathrm{Rs}$ - versus RyRs-mediated $\mathrm{Ca}^{2+}$ release following reperfusion injury in cardiomyocytes. $\mathrm{IP}_{3} \mathrm{Rs}$ are 
a
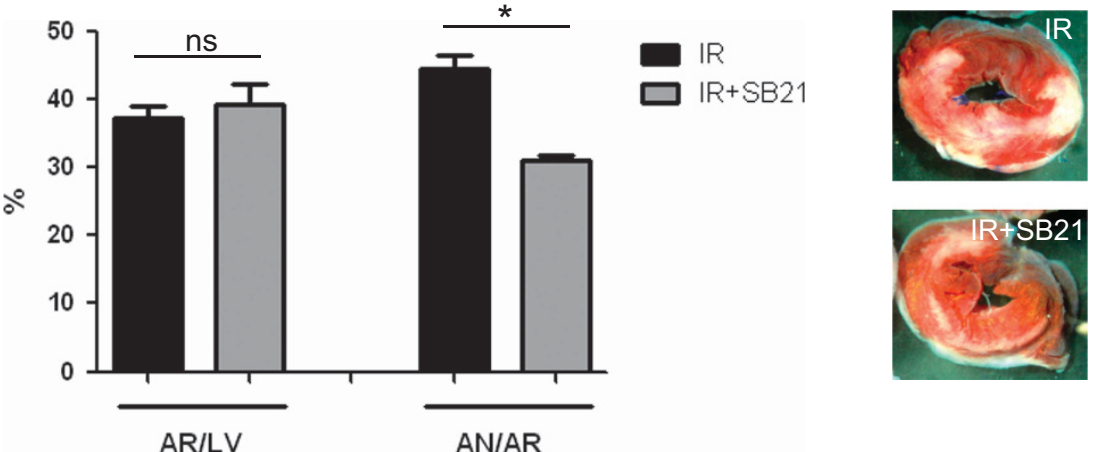

b

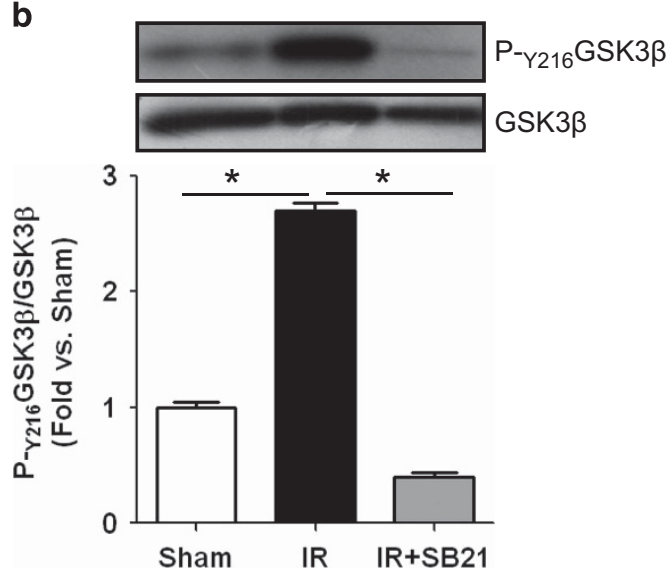

C
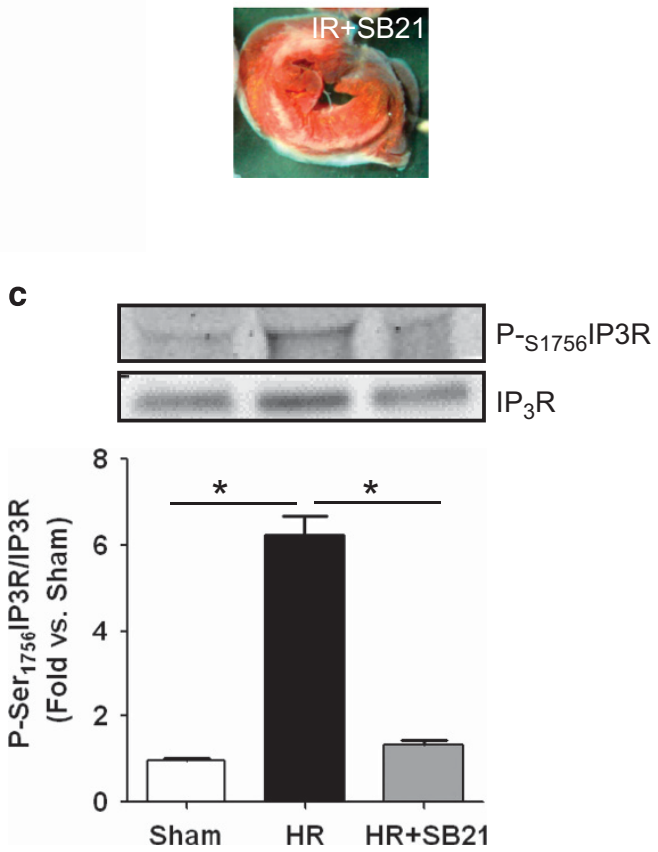

d

\section{IP: $I P_{3} R$}
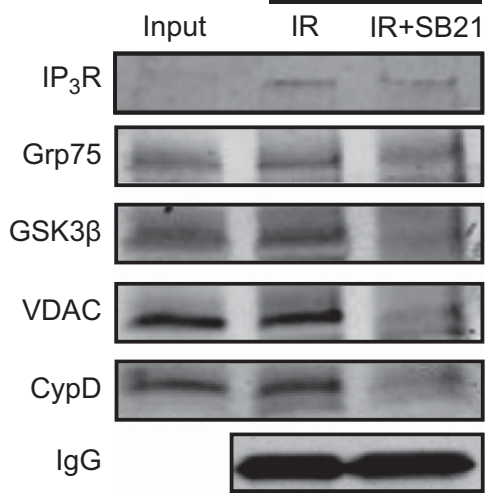

Figure 5 In vivo GSK3 $\beta$ inhibition-mediated cardioprotection is correlated to the inactivation of $I \mathrm{P}_{3} \mathrm{R}$ at reperfusion. (a) Cardioprotective effect of $\mathrm{SB} 21$ at reperfusion. Percentage of both area at risk (AR/LV) and area of necrosis (AN/AR) are presented for each groups ( $n=6$ per group). As illustrated in the right panel, injection of SB21 $(70 \mu \mathrm{g} / \mathrm{kg})$ at reperfusion reduced the size of myocardial infarction compared with IR group. (b) Relative GSK3 $\beta$ activity at reperfusion quantified by western immunoblotting of phospho-GSK3 $\beta$ (Tyr ${ }_{216}$, active form). Results were normalized with total GSK3 $\beta\left(n=4-5\right.$ distinct experiments per group). ${ }^{*} P<0.05$. (c) Immunoblotting of relative expression of phospho-Ser ${ }_{1756} I_{3} R$ revealed that $S B 21$ significantly reduced the activity of $I_{3} R$ during $I R$ injury. Results are means \pm S.E.M. ${ }^{*} P<0.05$ ( $n=4-6$ distinct experiments). (d) Hearts protected with SB21 $(70 \mu \mathrm{g} / \mathrm{kg})$ at reperfusion exhibited a clear reduction of $\mathrm{IP}_{3} \mathrm{R}$ interaction with Grp75, GSK3 $\beta$, VDAC and CypD. Results shown are one result representative of three trials

involved in cardiac $\mathrm{Ca}^{2+}$ signaling including the ECC in the normal heart, and also in some pathologies such as hypertrophy. ${ }^{19,25-27}$ Our data reinforce this idea as both pharmacologic and genetic inhibition of GSK3 $\beta$ leads to a decreased $\mathrm{Ca}^{2+}$ transfer from SR/ER to mitochondria, whereas overexpression of GSK3 $\beta$ enhances the entrance of $\mathrm{Ca}^{2+}$ into mitochondria under $\mathrm{IP}_{3} \mathrm{R}$ leak channel stimulation.

Whether GSK3 $\beta$ inhibition specifically impacts the $\mathrm{SR} / \mathrm{ER} \mathrm{Ca}^{2+}$ release or rather the $\mathrm{Ca}^{2+}$ entrance into mitochondria was not addressed in this study. Nevertheless, we demonstrated that pharmacological or genetic inhibition of GSK3 $\beta$ did not modify the mitochondrial membrane potential, indicating that the observed reduction of $\mathrm{Ca}^{2+}$ transfer from SR/ER to mitochondria was likely not the result of a limitation of the driving force between the two organelles.

Upon IR, the accumulation of $\mathrm{Ca}^{2+}$ into mitochondria is known to trigger PTP opening and cell death. ${ }^{28} \mathrm{Ca}^{2+}$ crosstalk 
between SR/ER and mitochondria has been involved in myocardial reperfusion injury. ${ }^{29}$ As cardioprotective mechanisms of GSK3 $\beta$ at reperfusion are still not clear, we hypothesized that GSK3 $\beta$ inhibition limits both cytosolic and mitochondrial $\mathrm{Ca}^{2+}$ overload by limiting $\mathrm{IP}_{3} \mathrm{R}$ channel opening and subsequent PTP-dependent cell death at reperfusion.

We demonstrated here that the interaction of GSK3 $\beta$ with all the partners of $\mathrm{IP}_{3} \mathrm{R} \mathrm{Ca}^{2+}$ channeling complex, including CypD, VDAC, Grp75 and $\mathrm{IP}_{3} \mathrm{R}$, was significantly increased after $\mathrm{HR}$ and associated with mitochondrial $\mathrm{Ca}^{2+}$ overload and cell death. Interestingly, the pharmacological inhibition of GSK3 $\beta$ not only decreased the interaction of GSK3 $\beta$ with the $\mathrm{Ca}^{2+}$ channeling complex but also decreased the protein composition of the $\mathrm{IP}_{3} \mathrm{R}$ channeling complex and attenuated both cytosolic and mitochondrial $\mathrm{Ca}^{2+}$ overload at reperfusion. This suggests that binding of $G S K 3 \beta$ to $I_{3} R$ may be responsible of the $\mathrm{Ca}^{2+}$ crosstalk between SR/ER and mitochondria during reperfusion injury.

Different observations were in favor of the causal connection of GSK $3 \beta$ with $\mathrm{IP}_{3} \mathrm{R}$ during IR. First, we provide in vivo and in vitro evidence that pharmacological inhibition of GSK3 $\beta$ reduced the physical interaction of GSK3 $\beta$ with $I_{3} R$ induced by IR. Second, the $\operatorname{Ser}_{1756}$ phosphorylation of $I P_{3} R$ was significantly reduced when GSK3 $\beta$ was inhibited at reperfusion. As a result, the open probability of the $\mathrm{Ca}^{2+}$ channels was reduced at reperfusion inducing a higher level of $\mathrm{Ca}^{2+}$ into $\mathrm{SR} / \mathrm{ER}$ lumen and a reduction of $\mathrm{Ca}^{2+}$ overload in both cytosol and mitochondria. Third, GSK3 $\beta$ inhibition at reperfusion reduced the interaction of $I P_{3} R$ with the other partners of the $\mathrm{Ca}^{2+}$ channeling complex including CypD, VDAC, Grp75 and GSK3 $\beta$.

Although $I P_{3} R 2$ is recognized as the predominant isoform in the cardiac myocyte, ${ }^{27} \mathrm{IP}_{3} \mathrm{R} 1$ is highly expressed in MAMs heart. $^{21,30,31}$ Our results show that GSK3 $\beta$ preferentially interacts with $I P_{3} R 1$, and can also interacts with $I P_{3} R 2$ and $\mathrm{IP}_{3} \mathrm{R} 3$ in cardiac cells (data not shown). In summary, we propose that inhibition of GSK3 $\beta$ might decrease the phosphorylation and the activity of $\mathrm{IP}_{3} R$, thereby limiting cytosolic and mitochondrial $\mathrm{Ca}^{2+}$ overload, possibly contributing to the reduction of both cell death and infarct size at reperfusion. Our proposal is in line with previous reports demonstrating that SR/ER loses almost $90 \%$ of its $\mathrm{Ca}^{2+}$ at the onset of reperfusion, ${ }^{32}$ and that specific $I P_{3} R$ channels inhibition can protect the heart at reperfusion. ${ }^{33}$ One may question whether $I P_{3} R$ may be a direct or an indirect substrate of GSK3 $\beta$. Such mechanism remains to be investigated indepth in future studies. However, our results showed (1) a positive correlation between the activity of GSK3 $\beta$ and the phosphorylation rate of $\mathrm{IP}_{3} \mathrm{R},(2)$ a linear correlation between the $\operatorname{Ser}_{1756}$ phosphorylation of $\mathrm{IP}_{3} \mathrm{R}$ and the protein-protein interaction of GSK3 $\beta$ with $\mathrm{IP}_{3} \mathrm{R}$ and (3) in silico analysis revealed at least two putative GSK3 $\beta$ phosphorylation sites on $I_{3} R$, Ser ${ }_{1756}$ and Ser $_{1765}$, reinforcing the notion that $I P_{3} R$ could be a substrate of GSK3 $\beta$.

Whether other factors may contribute to the increase of $\mathrm{Ca}^{2+}$ into SR/ER lumen upon inhibition of GSK3 $\beta$ at reperfusion remains to be determined (i.e. ANT, VDAC, CypD). Moreover, we cannot fully exclude a contribution of SERCA2 since Michael et al. ${ }^{12}$ previously demonstrated that overexpression of GSK3 $\beta$ could significantly reduce the expression of
SERCA2 in the heart. ${ }^{12}$ We noticed in the present work that SERCA2 expression seems to be increased when GSK3 $\beta$ was inhibited at the onset of reperfusion (data not shown). Such mechanism remains to be investigated in-depth in future studies, especially since a problem of timing has to be considered between the speed of $\mathrm{Ca}^{2+}$ response and the time needed for SERCA2 protein transcription at the onset of reperfusion.

To conclude, our work identifies a new role for GSK3 $\beta$ in cardioprotection as an important regulator of $\mathrm{Ca}^{2+}$ transfer between SR/ER and mitochondria during IR injury. We propose that GSK3 $\beta$ inhibition at reperfusion may protect heart through the limitation of SR/ER $\mathrm{Ca}^{2+}$ release by inhibition of $\mathrm{IP}_{3} \mathrm{R} \mathrm{Ca}^{2+}$ channeling complex and consecutive reduction of both cytosolic and mitochondrial $\mathrm{Ca}^{2+}$ overload and subsequent PTP opening.

\section{Materials and Methods}

Animals. The investigation conformed to the Guide for the Care and Use of Laboratory Animals published by the US National Institute of Health (NIH Publication No. 85-23, revised 1996) and was approved by the local institutional animal research committee (N BH2012-64 and 9011).

Subcellular fractionation. Cell fractionation was performed by differential ultracentrifugation as described previously. ${ }^{22,34}$ Briefly, hearts were homogenized with a glass potter in an isolation buffer $(225 \mathrm{mM}$ mannitol, $75 \mathrm{mM}$ sucrose, $0.5 \%$ $\mathrm{BSA}, 0.5 \mathrm{mM}$ EGTA and $30 \mathrm{mM}$ Tris- $\mathrm{HCl}, \mathrm{pH}$ 7.4). Both nuclei and cellular debris were then pelleted by two different centrifugations at $740 \times \mathrm{g}$ for $5 \mathrm{~min}$. The supernatant was centrifuged at $9000 \times g$ for 10 min to pellet crude mitochondria that were resuspended in mitochondria resuspending buffer (MRB) containing $250 \mathrm{mM}$ mannitol, $5 \mathrm{mM}$ HEPES and $0.5 \mathrm{mM}$ EGTA, pH 7.4. Resulting supernatant was further centrifuged at $20000 \times g$ for $30 \mathrm{~min}$ followed by $100000 \times g$ for $1 \mathrm{~h}$ to pellet the SR/ER

Purified mitochondria were obtained by centrifugation of crude mitochondria fraction through a Percoll medium at $95000 \times \mathrm{g}$ for $30 \mathrm{~min}$ in an SW40 rotor (Beckman Coulter, Villepinte, France). The resulting pellet was then washed two times in MRB by centrifugation at $6300 \times g$ for 10 min to obtain purified mitochondria.

To purify the MAM fraction localized in the diffused white band (under pure mitochondria band), MAM were diluted in MRB and centrifuged at $6300 \times \mathrm{g}$ for $10 \mathrm{~min}$ to remove any contaminating mitochondria. MAM supernatant was then centrifuged at $100000 \times g$ for $1 \mathrm{~h}$ in a 70 Ti rotor (Beckman Coulter) and the resulting pellet was resuspended in MRB. Protein content was assayed by the Lowry method for the following analysis.

Blue native and SDS-PAGE 2D separation. Hearts from wild-type (WT) mice were homogenized three times at $6000 \mathrm{~Hz}$ for $10 \mathrm{~s}$ (Precellys 24; Ozyme, Montigny-le-Bretonneux, France) in a buffer $(100 \mathrm{mM} \mathrm{KCl}, 50 \mathrm{mM}$ MOPS, $5 \mathrm{mM}$ $\mathrm{MgSO}_{4}, 1 \mathrm{mM}$ EGTA, $1 \mathrm{mM}$ ATP). Heart homogenates were then solubilized with $n$ dodecyl- $\beta$-D-maltopyranoside (detergent/protein ratio of $1.6: 1, \mathrm{~g} / \mathrm{g}$ ), combined with Coomassie Blue G-250 dye (detergent/dye ratio of 4:1, g/g) and separated on 4$16 \%$ Bis-Tris native PAGE gels (Invitrogen, Cergy Pontoise, France) for the first dimension. The first dimension gel was then excised and reduced with $1 \times$ NuPage reducing agent in $1 \times$ NuPage LDS sample buffer (Invitrogen) for $15 \mathrm{~min}$ at room temperature (RT). Cysteine alkylation was carried out with $\mathrm{N}, \mathrm{N}$-dimethylacrylamide for $15 \mathrm{~min}$ at RT. The reaction was quenched for $15 \mathrm{~min}$ at RT with $20 \%$ ethanol in $1 \times$ LDS and $0.1 \times$ reducing agent. Finally, the equilibrated gel strip was applied to the second dimension on a 4-16\% Criterion Bis-Tris gel, separated and transferred to the PVDF membrane.

IP and WB analysis. Total lysates of cardiac cells were prepared in lysis buffer containing 1\% NP40, $20 \mathrm{mM}$ Tris- $\mathrm{HCl}, 138 \mathrm{mM} \mathrm{NaCl}, 2.7 \mathrm{mM} \mathrm{KCl}, 1 \mathrm{mM} \mathrm{MgCl} 2,5 \%$ glycerol, $5 \mathrm{mM}$ EDTA, $1 \mathrm{mM}$ DTT supplemented with a cocktail of protease inhibitors (Sigma-Aldrich, Saint-Quentin Fallavier, France) and phosphatases inhibitors (PhosphoStop; Roche Diagnostics, Meylan, France). For IP, $2 \mu \mathrm{g}$ of antibodies directed against the protein of interest were added to the IP buffer (except for the control, which was supplemented with $2 \mu \mathrm{g}$ of anti-mouse $\operatorname{lgG}$ ). 
A range of $300-500 \mu \mathrm{g}$ of total protein (depending on the origin of the samples) was added in the previous mix and incubated overnight at $4{ }^{\circ} \mathrm{C}$. Fifty microliters of magnetic beads (Millipore, Fontenay sous Bois, France; no. LSKMAGG10) were then incubated for $2 \mathrm{~h}$ at $4{ }^{\circ} \mathrm{C}$ and finally precipitated with a strong magnet. After three washes in IP buffer, proteins were resuspended in Laemmli buffer and denatured at $95^{\circ} \mathrm{C}$ for $10 \mathrm{~min}$. Immunoprecipitated proteins were then analyzed by WB. Migration was performed in 4-20\% acrylamide gel and semidry blotter was used to transfer the proteins. All primary antibodies were used at a dilution of 1:1000, except CypD $(1: 4000)$. Mouse and rabbit secondary antibodies were incubated for $1 \mathrm{~h}$ at RT at 1:10000 (Bio-Rad, Marnes-la-Coquette, France). ECL+ reagent (GE Healthcare, Velizy-Villacoublay, France) was used for the membrane revelation, acquisition was performed with Bio-Rad Molecular Imager Gel Doc XR+, and ImageLab software was used for quantification (Bio-Rad). Antibodies IP3R (sc-28614), Grp75 (sc133137), P-GSK3 $\beta$ (sc-135653) and IgG (sc-66931) were from Santa Cruz Biotechnology (Dallas, TX, USA); P-IP3R (no. 8548), GSK3 $\beta$ (no. 9315), Serca2 (no. 4388), COXIV (cs no. 4844) and GAPDH (no. 2118) were from Cell Signaling Technology (Saint Quentin Yvelines, France); and VDAC (Ab14734), CypD (Ab110324) and RyR2 (Ab 117840) were from Abcam (Paris, France). Relative expressions of phosphorylated proteins were normalized to respective total form and results were expressed as fold versus basal condition.

Isolation of adult murine cardiomyocytes. Ventricular cardiomyocytes were isolated using enzymatic digestion according to previously described procedure. ${ }^{35,36}$ Briefly, WT mice were anesthetized with pentobarbital $(70 \mathrm{mg} / \mathrm{kg})$ (Sanofi Santé Animale, Libourne, France) and the heart was quickly harvested and retrogradely perfused at $37^{\circ} \mathrm{C}$ for $6-8 \mathrm{~min}$ with a perfusion buffer $(113 \mathrm{mM} \mathrm{NaCl}$, $4.7 \mathrm{mM} \mathrm{KCl}, 0.6 \mathrm{mM} \mathrm{KH}_{2} \mathrm{PO}_{4}, 0.6 \mathrm{mM} \mathrm{Na}_{2} \mathrm{HPO}_{4}, 1.2 \mathrm{mM} \mathrm{MgSO}_{4}, 12 \mathrm{mM} \mathrm{NaHCO}_{3}$, $10 \mathrm{mM} \mathrm{KHCO}, 10 \mathrm{mM}$ HEPES, $30 \mathrm{mM}$ Taurine, $\mathrm{pH}$ 7.4) containing $10 \mathrm{mM}$ 2,3-butanedione, $5.5 \mathrm{mM}$ glucose, $12.5 \mu \mathrm{M} \mathrm{CaCl}_{2}, 0.1 \mathrm{mg} / \mathrm{ml}$ of liberase (Roche) and $0.14 \mathrm{mg} / \mathrm{ml}$ trypsin (Sigma). Isolated myocytes were then maintained in culture in laminin- (10 $\mu \mathrm{g} / \mathrm{ml})$ precoated dishes with M199 medium (Invitrogen) and allowed to attach for $2 \mathrm{~h}$ before analysis.

Duolink in situ PLA. We used PLA experiments to evaluate the proximity of two proteins and their potential interaction $(<40 \mathrm{~nm})$ as described previously. ${ }^{22}$ Adult cardiomyocytes (or H9c2 cells) were plated into Lab-Tech slides (Thermo Scientific; no.155411). Cells were first fixed in $4 \%$ PFA for 10 min at RT. Cell permeabilization was carried out in $0.1 \%$ Triton X-100 for 15 min at RT followed by blocking for $30 \mathrm{~min}$ in a $37^{\circ} \mathrm{C}$ preheated humidity chamber. Primary antibodies directed against the two proteins of interest were then added at 1:200 and incubated overnight at $4^{\circ} \mathrm{C}$. From this point, each step was separated by two washes of $5 \mathrm{~min}$ in TBST and incubations were performed at $37^{\circ} \mathrm{C}$ in a humidity chamber. PLA probes, which are composed of antibodies linked to small complementary oligonucleotides, were added in accordance with the polarity for $1 \mathrm{~h}$. Ligation reaction was then performed for $30 \mathrm{~min}$ to ligate the complementary oligonucleotides. Polymerization of the ligated fragment was performed with a Taq polymerase (Duolink II in situ PLA; Olink Bioscience). Cells were then washed in $1 \times$ and $0.01 \times$ SSC buffer $(150 \mathrm{mM} \mathrm{NaCl}, 15 \mathrm{mM}$ sodium citrate for $1 \times)$ and dried at RT in the dark to preserve fluorescence. Slides were mounted in mounting medium containing DAPI and observed with a Leica SP5X confocal microscope (Wetzar, Germany). A maximum intensity projection created an output image from Z stack performed at $0.5 \mu \mathrm{m}$ depth. A total of $10-15$ cells were counted in each experiment $(n=7-16)$ for quantification. We used BlobFinder software (Image Analysis, Uppsala University, Uppsala, Sweden) to quantify the red dots corresponding to the positive interaction of the different proteins of interest.

Cytosolic, mitochondrial and SR/ER $\mathrm{Ca}^{2+}$ measurements. To monitor mitochondrial $\mathrm{Ca}^{2+}$, isolated adult cardiomyocytes (or $\mathrm{H} 9 \mathrm{c} 2$ cells) were loaded with $2.5 \mu \mathrm{M}$ rhod-2/AM (Molecular Probes, Eugene, OR, USA) for $30 \mathrm{~min}$ at $37^{\circ} \mathrm{C}$ in the presence of $0.003 \%(\mathrm{w} / \mathrm{v})$ pluronic acid. After $5 \mathrm{~h}$ de-esterification, cardiac cells were washed and placed in $1 \mathrm{ml}$ phenol-free DMEM to the heated stage $\left(37^{\circ} \mathrm{C}\right.$ ) of an inverted epifluorescence microscope (x40 oil-immersion objective) connected to a cooled CCD camera (PXL; Photometrics). Cytosolic $\mathrm{Ca}^{2+}$ dynamics were measured on $\mathrm{H} 9 \mathrm{c} 2$ loaded with $5 \mu \mathrm{M}$ fura-2/AM. Imaging was performed with a digital cooled CCD camera (Photometrics, Tucson, AZ, USA) on an inverted microscope (Nikon Diaphot, Melville, NY, USA) using a x40 oilimmersion objective. SR/ER $\mathrm{Ca}^{2+}$ level was measured with a FRET-based genetic sensor (D1ER), which allows quantification of $\mathrm{Ca}^{2+}$ because of its ratiometric properties. $^{37}$
Cellular models of HR. Adult cardiomyocytes or H9c2 were subjected to simulated hypoxia in a controlled hypoxic chamber (Adelbio, Clermont-Ferrand, France), induced by nitrogen flushing up to $1 \%$ partial $\mathrm{O}_{2}$ pressure for $45 \mathrm{~min}$ and $4 \mathrm{~h}$, respectively, in a Tyrode solution (130 $\mathrm{mM} \mathrm{NaCl}, 5 \mathrm{mM} \mathrm{KCl}, 10 \mathrm{mM}$ HEPES, $1 \mathrm{mM}$ $\mathrm{MgCl}_{2}, 1.8 \mathrm{mM} \mathrm{CaCl}_{2}$ at pH $7.4 / 37^{\circ} \mathrm{C}$ ) followed by $2 \mathrm{~h}$ of reoxygenation at $37^{\circ} \mathrm{C}$ in normal culture medium. Cells received vehicle with no additional intervention (HR) or $6 \mu \mathrm{M} \mathrm{SB} 21$ (HR+SB21) at the onset of reoxygenation. Time control group consisted of cells without the hypoxic stimulus. Cell death was measured by counting PI-positive cells by imaging or flow cytometry (FACSCalibur; BD Biosciences, Le Pont de Claix, France) at the end of the reperfusion period.

In vivo model of acute myocardial IR injury. C57BL/6 J (male, 8-10 weeks old) were anesthetized by intraperitoneal mixture of $70 \mathrm{mg} / \mathrm{kg}$ pentobarbital sodium and $0.1 \mathrm{mg} / \mathrm{kg}$ buprenorphine as described previously. ${ }^{7,38-40}$ The animals were orally intubated, ventilated and body temperature was maintained at $37^{\circ} \mathrm{C}$. A left thoracotomy was performed in the fourth intercostal space. A small curved needle was passed around the left anterior descending coronary artery to induce IR. Mice were subjected to $45 \mathrm{~min}$ regional myocardial ischemia followed by $24 \mathrm{~h}$ reperfusion. Myocardial infarct size was then determined by triphenyltetrazolium staining as described previously. ${ }^{7,38-40}$

Statistical analysis. Data are presented as mean \pm S.E.M., unless otherwise specified. Statistical analysis was performed with GraphPad Prism 5 software (La Jolla, CA, USA) with the use of nonparametric tests. Comparisons among $>2$ groups were analyzed by the Kruskal-Wallis test. When the Kruskal-Wallis test was significant, the Dunn's appropriate multiple testing procedure was performed. For all other analysis, data were compared by the Mann-Whitney rank-sum test. Statistical significance was defined as a value of $P<0.05$.

\section{Conflict of Interest}

The authors declare no conflict of interest.

Acknowledgements. LG was supported by French Grant EXPLORA'PRO 2013. We thank Prof. Dr. Roger Tsien for D1ER plasmid, the MitoCare center (Thomas Jefferson University Philadelphia, Philadelphia, PA, USA) and the CeCile Imaging Center (Lyon, France) for their assistance and advices in imaging analysis. We extend our thanks to Steve Hurst for his careful review of the manuscript.

1. Embi N, Rylatt DB, Cohen P. Glycogen synthase kinase-3 from rabbit skeletal muscle. Separation from cyclic-amp-dependent protein kinase and phosphorylase kinase. Eur $J$ Biochem 1980; 107: 519-527.

2. Woodgett JR, Cohen P. Multisite phosphorylation of glycogen synthase. Molecular basis for the substrate specificity of glycogen synthase kinase-3 and casein kinase-ii (glycogen synthase kinase-5). Biochim Biophys Acta 1984; 788: 339-347.

3. Woodgett JR. Molecular cloning and expression of glycogen synthase kinase-3/factor a. EMBO J 1990; 9: 2431-2438.

4. Cross DA, Alessi DR, Cohen P, Andjelkovich M, Hemmings BA. Inhibition of glycogen synthase kinase-3 by insulin mediated by protein kinase b. Nature 1995; 378: 785-789.

5. Antos CL, McKinsey TA, Frey N, Kutschke W, McAnally J, Shelton JM et al. Activated glycogen synthase-3beta suppresses cardiac hypertrophy in vivo 10.1073/pnas.231619298. Proc Natl Acad Sci USA 2002; 99: 907-912.

6. Tong H, Imahashi K, Steenbergen C, Murphy E. Phosphorylation of glycogen synthase kinase-3beta during preconditioning through a phosphatidylinositol-3-kinase-dependent pathway is cardioprotective. Circ Res 2002; 90: 377-379.

7. Gomez L, Paillard M, Thibault H, Derumeaux G, Ovize M. Inhibition of gsk3beta by postconditioning is required to prevent opening of the mitochondrial permeability transition pore during reperfusion. Circulation 2008; 117: 2761-2768.

8. Juhaszova M, Zorov DB, Kim SH, Pepe S, Fu Q, Fishbein KW et al. Glycogen synthase kinase-3beta mediates convergence of protection signaling to inhibit the mitochondrial permeability transition pore. J Clin Invest 2004; 113: 1535-1549.

9. Nishihara M, Miura T, Miki T, Tanno M, Yano T, Naitoh $\mathrm{K}$ et al. Modulation of the mitochondrial permeability transition pore complex in gsk-3[beta]-mediated myocardial protection. J Mol Cell Cardiol 2007; 43: 564-570.

10. Pastorino JG, Hoek JB, Shulga N. Activation of glycogen synthase kinase 3beta disrupts the binding of hexokinase ii to mitochondria by phosphorylating voltage-dependent anion channel and potentiates chemotherapy-induced cytotoxicity. Cancer Res. 2005; 65: 10545-10554.

11. Rasola A, Sciacovelli M, Chiara F, Pantic B, Brusilow WS, Bernardi P. Activation of mitochondrial erk protects cancer cells from death through inhibition of the permeability transition. Proc Natl Acad Sci USA 2010; 107: 726-731. 
12. Michael A, Haq S, Chen X, Hsich E, Cui L, Walters B et al. Glycogen synthase kinase-3beta regulates growth, calcium homeostasis, and diastolic function in the heart. J Biol Chem 2004; 279: 21383-21393

13. Tanno M, Kuno A, Ishikawa S, Miki T, Kouzu H, Yano T et al. Translocation of glycogen synthase kinase-3beta (gsk-3beta), a trigger of permeability transition, is kinase activitydependent and mediated by interaction with voltage-dependent anion channel 2 (vdac2). J Biol Chem 2014; 289: 29285-29296.

14. Braunwald E, Kloner RA. Myocardial reperfusion: a double-edged sword? J Clin Invest 1985 76: 1713-1719.

15. Borgers M, Thone F, Van Reempts J, Verheyen F. The role of calcium in cellular dysfunction. Am J Emerg Med. 1983; 1: 154-161.

16. Rizzuto R, Marchi S, Bonora M, Aguiari P, Bononi A, De Stefani D et al. $\mathrm{Ca}(2+)$ transfer from the ER to mitochondria: When, how and why. Biochim Biophys Acta 2009; 1787: 1342-1351.

17. Bers DM. Cardiac excitation-contraction coupling. Nature 2002; 415: 198-205

18. Domenech RJ, Sanchez G, Donoso P, Parra V, Macho P. Effect of tachycardia on myocardial sarcoplasmic reticulum and $\mathrm{Ca}^{2+}$ dynamics: a mechanism for preconditioning? J Mol Cell Cardiol 2003; 35: 1429-1437.

19. Signore S, Sorrentino A, Ferreira-Martins J, Kannappan R, Shafaie M, Del Ben F et al. Inositol 1, 4, 5-trisphosphate receptors and human left ventricular myocytes. Circulation 2013; 128: 1286-1297.

20. Hayashi T, Su TP. Sigma-1 receptor chaperones at the er-mitochondrion interface regulate $\mathrm{Ca}(2+)$ signaling and cell survival. Cell 2007; 131: 596-610.

21. Szabadkai G, Bianchi K, Varnai $P$, De Stefani D, Wieckowski MR, Cavagna D et al. Chaperone-mediated coupling of endoplasmic reticulum and mitochondrial $\mathrm{Ca}^{2+}$ channels. $J$ Cell Biol 2006; 175: 901-911.

22. Paillard M, Tubbs E, Thiebaut PA, Gomez L, Fauconnier J, Da Silva CC et al. Depressing mitochondria-reticulum interactions protects cardiomyocytes from lethal hypoxiareoxygenation injury. Circulation 2013; 128: 1555-1565.

23. Louch WE, Sheehan KA, Wolska BM. Methods in cardiomyocyte isolation, culture, and gene transfer. J Mol Cell Cardiol 2011; 51: 288-298.

24. McCombs JE, Palmer AE. Measuring calcium dynamics in living cells with genetically encodable calcium indicators. Methods 2008; 46: 152-159.

25. Kijima Y, Saito A, Jetton TL, Magnuson MA, Fleischer S. Different intracellular localization of inositol 1,4,5-trisphosphate and ryanodine receptors in cardiomyocytes. J Biol Chem 1993 268: 3499-3506.

26. Tuvia S, Buhusi M, Davis L, Reedy M, Bennett V. Ankyrin-b is required for intracellular sorting of structurally diverse $\mathrm{Ca}^{2+}$ homeostasis proteins. J Cell Biol 1999; 147 : 995-1008.

27. Vermassen E, Parys JB, Mauger JP. Subcellular distribution of the inositol 1,4,5trisphosphate receptors: functional relevance and molecular determinants. Biol Cell 2004; 96: 3-17.
28. Crompton M, Virji S, Ward JM. Cyclophilin-d binds strongly to complexes of the voltagedependent anion channel and the adenine nucleotide translocase to form the permeability transition pore. Eur J Biochem 1998; 258: 729-735.

29. Garcia-Dorado D, Ruiz-Meana M, Inserte J, Rodriguez-Sinovas A, Piper HM. Calcium-mediated cell death during myocardial reperfusion. Cardiovasc Res 2012; 94: 168-180.

30. Mendes CC, Gomes DA, Thompson M, Souto NC, Goes TS, Goes AM et al. The type III inositol 1,4,5-trisphosphate receptor preferentially transmits apoptotic $\mathrm{Ca}^{2+}$ signals into mitochondria. J Biol Chem 2005; 280: 40892-40900

31. Anger M, Lompre AM, Vallot O, Marotte F, Rappaport L, Samuel JL. Cellular distribution of $\mathrm{Ca}^{2+}$ pumps and $\mathrm{Ca}^{2+}$ release channels in rat cardiac hypertrophy induced by aortic stenosis. Circulation 1998; 98: 2477-2486.

32. Frolkis VV, Frolkis RA, Mkhitarian LS, Fraifeld VE. Age-dependent effects of ischemia and reperfusion on cardiac function and $\mathrm{Ca}^{2+}$ transport in myocardium. Gerontology 1991; 37: 233-239.

33. Gysembergh A, Lemaire S, Piot C, Sportouch C, Richard S, Kloner RA et al. Pharmacological manipulation of $\operatorname{Ins}(1,4,5) \mathrm{p} 3$ signaling mimics preconditioning in rabbit heart. Am J Physiol 1999; 277: H2458-H2469.

34. Wieckowski MR. The role of mitochondrial permeability transition pore in physiology and pathology of the cell]. Postepy Biochem 2008; 54: 71-81.

35. Obame FN, Plin-Mercier C, Assaly R, Zini R, Dubois-Rande JL, Berdeaux A et al. Cardioprotective effect of morphine and a blocker of glycogen synthase kinase 3 beta, sb216763 [3-(2,4-dichlorophenyl)-4(1-methyl-1 $h$-indol-3-yl)-1 $h$-pyrrole-2,5-dione], via inhibition of the mitochondrial permeability transition pore. J Pharmacol Exp Ther 2008; 326: 252-258.

36. Li J, Gao E, Vite A, Yi R, Gomez L et al. Alpha-catenins control cardiomyocyte proliferation by regulating yap activity. Circ Res 2014; 116: 70-79.

37. Palmer AE, Jin C, Reed JC, Tsien RY. Bcl-2-mediated alterations in endoplasmic reticulum $\mathrm{Ca}^{2+}$ analyzed with an improved genetically encoded fluorescent sensor. Proc Natl Acad Sci USA 2004; 101: 17404-17409.

38. Gomez L, Chavanis N, Argaud L, Chalabreysse L, Gateau-Roesch O, Ninet J et al. Fas-independent mitochondrial damage triggers cardiomyocyte death after ischemiareperfusion. Am J Physiol Heart Circ Physiol 2005; 289: H2153-H2158.

39. Gomez L, Paillard M, Price M, Chen Q, Teixeira G, Spiegel S et al. A novel role for mitochondrial sphingosine-1-phosphate produced by sphingosine kinase-2 in PTP-mediated cell survival during cardioprotection. Basic Res Cardiol 2011; 106: 1341-1353.

40. Gomez L, Thibault H, Gharib A, Dumont JM, Vuagniaux G, Scalfaro P et al. Inhibition of mitochondrial permeability transition improves functional recovery and reduces mortality following acute myocardial infarction in mice. Am J Physiol Heart Circ Physiol 2007; 293: H1654-H1661.

\section{Supplementary Information accompanies this paper on Cell Death and Differentiation website (http://www.nature.com/cdd)}

